\title{
Milieux et peuplements en Bas-Dauphiné
}

Jean-François Berger

URL : http://journals.openedition.org/adlfi/6788

ISSN : 2114-0502

Éditeur

Ministère de la culture

\section{Référence électronique}

Jean-François Berger, " Milieux et peuplements en Bas-Dauphiné », ADLFI. Archéologie de la France Informations [En ligne], Rhône-Alpes, mis en ligne le 01 mars 2007, consulté le 19 avril 2019. URL :

http://journals.openedition.org/adlfi/6788

Ce document a été généré automatiquement le 19 avril 2019

(c) Ministère de la Culture et de la Communication, CNRS 


\title{
Milieux et peuplements en Bas- Dauphiné
}

\author{
Jean-François Berger
}

Date de l'opération : 2007 (PC)

\section{L'étude des sources historiques et cartographiques depuis la fin du Moyen Âge}

1 La période comprise entre la fin du Moyen Âge et le XIX ${ }^{e}$ s. a fait l'objet de nouvelles recherches en 2007 qui documentent l'occupation et la gestion du sol et la démographie historique des quatre ou cinq derniers siècles, une période qui a vu un développement sociétal considérable dans les milieux palustres et alluviaux des Basses Terres dauphinoises, lors d'un épisode de péjoration des conditions hydroclimatiques pluriséculaires (petit âge Glaciaire).

2 La gestion de l'hydraulique agricole entre le Moyen Âge et le XIX ${ }^{e}$ s. (N. Bernigaud) est restituée à partir des autorisations de la chambre des comptes de Grenoble qui accordent à des particuliers le droit de dériver l'eau des rivières (aigage), pour l'arrosage des prairies et des vergers ainsi que l'alimentation des moulins. À partir d'une série de documents datés entre le $\mathrm{XIV}^{\mathrm{e}} \mathrm{s}$. et le $\mathrm{XVI}^{\mathrm{e}} \mathrm{s}$., on remarque à partir du début du XVI $\mathrm{s}$. une multiplication des autorisations accordées, qui attestent un développement important de l'hydraulique dans la région. La noblesse et la bourgeoisie investissent dans la production de foin et de noix (cultures irriguées) ainsi que la force hydromotrice pour la meunerie. Le développement de l'énergie hydraulique est surtout lié à l'essor de l'industrie textile et on constate la multiplication des battoirs à chanvre et des gauchoirs à draps le long des rivières. On peut se demander si le petit âge Glaciaire n'a pas concouru au développement des usages hydrauliques en augmentant l'hydrodynamisme des rivières. 
3 Le dépouillement effectué par M. Goy pour la période médiévale nous apporte des éléments variés sur les maisons fortes, les crues du Rhône et du Guiers, les zones humides (léchères, marais, prémarais (paquis), étangs, brotteaux, bras ou eaux mortes, tourbières, etc.), l'hydraulique (moulins) et les pratiques agraires et piscicoles des XVe $s$. au XVII $s$. Le dépouillement des fonds dans les mairies de la zone d'étude (Bouchage, Morestel, Corbelin, Granieu et les Avenières) a également été poursuivi par S. Perrin-Toinin pour les périodes moderne et contemporaine. Il a concerné les BMS des XVII ${ }^{e} s$. au XX $\mathrm{X}$. (jusqu'en 1952), les registres des délibérations de conseils municipaux (XVII ${ }^{\mathrm{e}} \mathrm{s}$. au XX $\mathrm{X}$ s.), les archives concernant le couvert forestier, l'extraction de tourbières, le Rhône, les propriétés communales, les archives concernant les travaux divers au XVII ${ }^{e}$ s. et $\mathrm{XX}^{\mathrm{e}} \mathrm{s}$., les recensements de populations du XVII ${ }^{e} s$. et XXe $s$., le parcellaire de 1646 pour les Avenières. L'essentiel des archives consultées en mairie se compose de papiers, registres, lettres, comptes et plans répertoriant les divers travaux engagés par les communautés d'habitants vis-à-vis des contraintes naturelles (marais, inondations du Rhône, amélioration des conditions de circulation dans un terroir bien humide et insalubre notamment pour le Bouchage).

Ces archives nous renseignent sur la nature du couvert forestier, sur l'étendue des propriétés communales et leur valeur financière, sur les conflits de propriétés importants dans cette société d'Ancien Régime. Elles montrent aussi les rapports entre l'homme et ce marais qu'il exploite fortement et ses évolutions avec les tentatives d'assèchements.

Dans l'axe fluvial du Rhône entre la confluence Rhône-Guiers (Aoste) et le bassin de Malville l'étude des systèmes agraires, le dépouillement de l'enquête Bouchu (révision des feux des paroisses) de 1702 effectué par G. Gaucherau service des Archives départementales de l'Isère (ADI) apporte également de nombreuses informations sur les productions et les systèmes agraires du tout début du XVIII ${ }^{e} \mathrm{~s}$. Les systèmes agraires apparaissent particulièrement déterminés par les qualités pédologiques des sols, avec une partition entre terroirs marqués par un accès importants aux alluvions du Rhône (les Basses Terres) et terroirs arides et moins fertiles des terrasses et moraines quaternaires et des reliefs proches, calcaires ou mollassiques (bassin de Malville). Cette organisation agricole pourrait même être en place dès le XlV ${ }^{e} s$. d'après les données recueillies dans les inventaires de Châtellenie de Quirieu. Les sources écrites nous apportent également des informations plus directes sur les relations entre les sociétés et les dynamiques hydrologiques au cours du PAG. Un premier recensement des crues depuis le Moyen Âge (milieu du XlV ${ }^{\mathrm{e}} \mathrm{s}$ ) montre les conséquences variées pour les sociétés comme les destructions des villages, des aménagements fluviaux comme les bacs et les ponts, les engravements de terres qui rendent les terrains impropres aux cultures ou encore les recoupements de méandres du Rhône qui multiplient les conflits d'usage et les plaintes entre riverains des berges dauphinoises et savoyardes. Les dernières données permettraient de repousser au début du XVII ${ }^{\mathrm{e}} \mathrm{s}$. la progradation d'une charge de fond gravelocaillouteuse dans le lit du Rhône, associée à une métamorphose de son cours vers un style en tresses.

6 Ces documents devront être traités globalement afin de mettre en lumière les modifications du paysage dans leur globalité historique, hydrologique, topographique, agraire et techno-économique. Leur intégration dans le SIG du PCR, dans les limites imposées par les éléments de localisation, devrait nous permettre de proposer des cartes paléogéographiques des Basses Terres pour la fin du Moyen Âge et proposer des modèles 
d'interactions société-milieu pour les périodes moderne et contemporaine, importantes pour la compréhension des sources plus anciennes recueillies dans la même zone d'étude.

\section{Les études archéologiques de terrain}

7 Parallèlement, les études de terrain orientées autour de la reconstitution du peuplement (prospections pédestres et aériennes), des paysages et des climats anciens (photointerprétation, sondages et carottages géoarchéologiques) se poursuivent. Plusieurs missions de terrain ont été effectuées jusqu'à la fin de l'année 2007 pour pouvoir accéder aux parcelles cultivées. Des prospections systématiques avec relevés du mobilier théodolithe laser ont été menées sur un site à haut potentiel archéologique (cœur de l'agglomération secondaire d'Aoste: plateau des «Côtes, Saint-Pierre, La Planche») (S. Bleu, V. Vachon et G. Gaucher). Des prospections géophysiques ont été menées en début novembre 2007 sur les parcelles jouxtant l'officine de potier de Normandoz à Aoste, datée de la fin du Moyen Âge. Elles ont été réalisées par l'entreprise Terra Nova et ont permis de compléter la cartographie des fours, des zones de rejets des ratés de cuisson et d'autres structures associées sur la parcelle située en face de celle qui a fait l'objet d'une fouille par l'INRAP (A. Horry) en 2006. Cette prospection a également permis d'identifier avec précision le tracé d'une voie romaine située à la sortie occidentale du vicus d'Aoste. Un sondage a été entrepris sur le petit édicule identifié en 2004, montée Saint-Pierre. Un probable puits rituel, a été identifié, indiquant peut-être la présence d'un sanctuaire dans ce secteur. D'autres éléments en notre possession nous permettent de le supposer (point dominant de l'édifice, oscillum, nombreuses découvertes monétaires, mur de clôture, structure de douze mètres de diamètre avec des murs de trois mètres d'épaisseur, etc.).

\section{Les études archéologiques et paléoenvironnementales associées aux opérations d'archéologie préventive}

8 L'opération d'archéologie préventive de la ZAC de la Maladière (Bourgoin-Jallieu) sous la responsabilité de l'INRAP a représenté la principale opération de l'année 2007 pour le PCR. Elle a réuni des approches archéologiques, paléopaysagères, agraires et paléoenvironnementales. Un système d'information géographique (SIG) a été mis en place autour de cette opération pour faciliter l'analyse régressive du paysage, les reconstitutions paléogéographiques et chronostratigraphiques (logiciels ArcGis et Rockworks).

Les datations radiocarbones (vingt dates AMS) et dendrochronologiques (trente deux pieux en chêne) réalisées sur l'ensemble des structures mettent en évidence la création d'un parcellaire à la fin du $\mathrm{I}^{\mathrm{er}} \mathrm{s}$. apr. J.-C. Le découpage foncier de cette partie du marais est accompagné par la mise en place de structures d'exploitations tels un probable moulin gallo-romain avec son bief et des levées en pierre sèche (structure encore inconnue dans la région pour cette époque) et un système de canaux d'irrigation. La mise en place de cette organisation hydraulique, détournant les eaux de la Bourbre à des fins agricoles et de meunerie s'accompagne de la création d'un semis de petits sites au début du Ile siècle de notre ère au cœur du marais de Bourgoin (thèse en cours de N. Bernigaud). Elle correspond donc à un véritable investissement foncier, probablement aux dépens d'un secteur qui faisait jusqu'alors partie de l'ager publicus. Une importante crise hydro- 
sédimentaire datée du début $\mathrm{du}_{\mathrm{IV}}{ }^{\mathrm{e}} \mathrm{s}$. désorganise ce réseau hydraulique (envahissement des canaux et biefs par une nappe gravelocaillouteuse), contribuant probablement à son abandon vers cette période. Dans la seconde moitié $d u V^{e} s$. un nouveau système d'irrigation est installé en partie dans l'axe du premier réseau, mais sa durée d'utilisation reste pour le moment inconnue au-delà du $\mathrm{VI}^{\mathrm{e}} \mathrm{s}$. (dates en cours). Dans l'optique de replacer les aménagements agraires antiques et le site Néolithique final dans un cadre paléohydrologique et environnemental, d'importantes études géoarchéologiques et paléobotaniques ont été mises en place. O. Franc (INRAP) a relevé de manière systématique plusieurs centaines de coupes stratigraphiques, qui ont ensuite été intégrées dans un logiciel de restitution 3D (Rockworks) après une codification préalable. Ce travail novateur et expérimental sera poursuivi dans le cadre du PCR avec les géomaticiens du Cepam pour être publié. Un transect de carottes géologiques (de $5 \mathrm{~m}$ à $6 \mathrm{~m}$ ) a été effectué depuis les anciennes berges du lac jusque dans la partie immergée jusqu'à récemment et associée à une épaisse couche tourbeuse sur les photographies aériennes, avec l'aide du carottier mécanique de l'UMR 5140 de Lattes. Les cinq carottes prélevées feront l'objet d'études géophysiques, géochimiques, sédimentologiques et botaniques dans les deux ou trois années à venir dans le cadre du PCR et d'une ANR sur les Alpes du Nord, afin de dresser un cadre paléohydrologique et végétal de référence sur cette partie du nord Dauphiné (coord. J.-F. Berger).

Un autre diagnostic de l'INRAP réalisé sur le site de La Pelisse et du Marais à Cessieu, dans la moyenne vallée de la Bourbre, a révélé la présence d'un niveau archéologique du Bronze final I, localisé en pied de pente et en bord de rivière. Ce niveau d'occupation est caractérisé par la présence d'un important mobilier céramique et lithique, associé à un niveau à galets thermofractés reposant sur un paléosol brunifié (étude S. Bleu, J.$\mathrm{M}$. Treffort et $\mathrm{O}$. Franc). Il s'agit vraisemblablement de foyers de cuisson à but culinaires situés à une certaine distance des espaces habités. L'occupation de l'âge du Bronze n'est connue dans le Nord Dauphiné que par quelques sépultures et découvertes isolées, et par des occupations en cavités karstiques le long de la montagne du Bugey ou des falaises de la Balme.

11 Les quelques découvertes fortuites de sites de l'âge du Bronze ou du premier âge du Fer, enterrés en fond de vallée fluviale, entre la confluence Rhône-Guiers (Aoste), les berges du Girondan à Saint-Romain-de-Jalionas et la basse et la moyenne vallée de la Bourbre (Cessieu, Saint-Quentin-Fallavier), laissent augurer un potentiel nettement plus important pour cette période de l'Holocène, qui devra être pris en compte lors des diagnostics qui seront conduits sur la future voie du TGV Lyon-Turin.

Un dernier diagnostic réalisé dans le bourg d'Aoste, place de la Mairie, en décembre 2007 a permis de confirmer la présence d'un important bâtiment gallo-romain au nord de l'église avec présence d'un bassin muni d'une exèdre (péristyle ?). Cette donnée se rajoute à celles obtenues au cours des dernières années dans le cadre de diagnostics réalisés dans le village ou sur ses marges. Le dossier sur la topographie du vicus d'Aoste prend ainsi forme année après année, il fera l'objet d'un paragraphe synthétique sous la direction de S. Bleu dans le volume de la CAG Nord-Isère. 


\section{Les analyses sur la paléodynamique et les paléoenvironnements fluviaux}

Les analyses se sont poursuivies sur les séquences fluviales du Rhône antique dans le secteur de la Cour du Pont, au pied de la butte des Avenières. Les nouvelles données paléohydrologiques et chronologiques absolues obtenues contribuent à renforcer les hypothèses chronologiques émises lors du rapport 2005, à propos de l'épisode de perturbation majeure qu'a subit l'hydrosystème des Basses Terres dauphinoises dans l'Antiquité. La défluviation du Rhône, correspondant à l'abandon de son cours des Avenières et à la création d'un nouveau cours à travers la vallée de Brégnier-Cordon, se situe bien à la charnière $\mathrm{I}^{\mathrm{er}} \mathrm{s}$. et II $\mathrm{s}$. apr. J.-C. Les données radiocarbone et sédimentaires mettent aussi en évidence un épisode détritique important dans le bras mort du Rhône à la transition Bas-Empire - haut Moyen Âge ( $\mathrm{V}^{\mathrm{e}} \mathrm{s}$. et $\mathrm{VI}^{\mathrm{e}} \mathrm{s}$.) avant une longue phase de stabilité du secteur associée au développement d'un marais plus ou moins en eau (tourbe noire épaisse) jusqu'aux XIle $s$. et XIIl ${ }^{\mathrm{e}} \mathrm{s}$. Les aménagements en bois retrouvés sur la berge droite fossile du Rhône en 2006, d'abord identifiés comme une passerelle ou un ponton permettant de traverser la lône, sont envisagés aujourd'hui comme les vestiges d'une pêcherie (observation d'une possible nasse écrasée sur place) d'âge médiéval (évalué entre 600 apr.J.-C et 1100 apr.J.-C.). Une courte opération (automne 2007) destinée à vérifier la véracité de cette hypothèse a été effectuée durant l'automne. Elle a permis de retrouver une nasse en bois blanc, en place à la base de la tourbe médiévale qui a été prélevée et envoyée pour restauration à Arcnucléart, en collaboration avec le conservateur du musée d'Aoste.

\section{La mise en place des agrosystèmes hydrauliques}

Les aménagements hydrauliques mis au jour dans la cuvette de la Verpillère en 2006 ont fait l'objet de plusieurs datations radiocarbone, qui confirment l'existence de réseaux d'irrigation protohistoriques (dès le $\mathrm{V}^{\mathrm{e}} \mathrm{s}$. av. J.-C.) alimentés par des captages effectués sur un paléocours de la Bourbre. Ils complètent les données initialement acquises sur les sites des Canaux plus à l'ouest et du Vernai à Saint-Romain-de-Jalionas et confirment ainsi l'ancienneté de l'utilisation de l'hydraulique dans ce secteur occupé par le peuple des Allobroges. Ils sont associés à d'autres réseaux d'âge antique qui se déploient sur de plus vastes surfaces dans les secteurs alluviaux et palustres de l'Isle Crémieu.

BERGER Jean-François et l'équipe inter-institutionnelle du PCR 
INDEX

operation Projet collectif de recherche (PCR)

Index chronologique : âge du Bronze, âge du Fer, Empire romain, ép. contemporaine, Moyen Âge*, Néolithique final, XIVe siècle apr. J.-C., XIXe siècle apr. J.-C., XVe siècle apr. J.-C., XVIe siècle apr. J.-C.

\section{AUTEURS}

JEAN-FRANÇOIS BERGER

CNRS 